\title{
Scleral Necrosis Following Pterygium Excision: A Case Report
}

\author{
Bade Ogundipe $^{1}$, Olubusayo O.Adejumo ${ }^{2,3}$, Benedictus G.K Ajayi ${ }^{3}$, Izuka A.Okwudishu ${ }^{4}$, Omodele O.A Jagun ${ }^{5}$, \\ Caroline O.Adeoti ${ }^{6}$ \\ ${ }^{1,4}$ Department of Ophthalmology, UCH, Ibadan, Nigeria \\ ${ }^{2}$ Eleta Eye Institute, Ibadan, Nigeria \\ 2, 3,6 Ophthalmology Department, Osun State University Teaching Hospital, Osogbo, Nigeria. \\ ${ }^{5}$ Ophthalmology unit, Babcock University Teaching Hospital, Ilishan-Remo, Nigeria
}

\begin{abstract}
Purpose: To report a case of scleral necrosis after pterygium excision and the management.

Method: Case report of a healthy young woman who presented with poor vision and scleral necrosis following nasal recurrent pterygium excision with adjunct beta irradiation in October 2020 at Eleta Eye Institute, Ibadan, Nigeria.
\end{abstract}

Results: Marked improvement in visual recovery by two months post-operative with corneo-scleral patch.

Conclusion: Prompt treatment with corneo-scleral patch and topical steroid can help avert the vision loss and possible loss of eye integrity that can follow surgically induced scleral necrosis.

Keywords: Pterygium, scleral necrosis, corneo-scleral graft, visual recovery.

\section{INTRODUCTION}

A pterygium is a wing-shaped, fibrovascular growth on the conjunctiva; which could extend across the limbus, invading the corneal surface. It is postulated to result from actinic damage to the limbal stem cells, hence, considered a focal limbal stem cell deficiency (Ronald, 2018). The most challenging aspect of pterygium excision is the high incidence of recurrence, as high as $88 \%$ with simple excision involving an uncovered bare sclera(Ronald, 2018; Noureddin G, \&Yeung, S, 2016). The management options for prevention of pterygium recurrence are conjunctival autografting, amniotic membrane grafting and the use of adjuvant therapies including mitomycin C( MMC), 5-fluorouracil, anti-vascular endothelial growth factor (anti-VEGF) agents, and beta-irradiation (Noureddin G, \&Yeung, S, 2016).

Complications following pterygium excision includes infection, diplopia, cornea perforation, cornea scarring and granuloma, rarely, globe perforation, scleral necrosis, vitreous hemorrhage and retinal detachment. Scleral necrosis or melting is a rare complication that may develop following pterygium surgery and it can lead to blindness (Linna, LU et al, 2017). Infection, ischemia and hypersensitivity response are possible pathological mechanisms underlying scleral necrosis following pterygium surgery (Linna, et al, 2017). The use of adjunctive MMC and beta- irradiation may increase the likelihood of scleral necrosis following pterygium excision (Linna, et al, 2017).
The treatment of scleral necrosis includes the use of antibiotics, systemic immunosuppressive drugs and surgical repair of the scleral defect with a variety of graft materials(Linna, et al, 2017).

\section{METHOD}

We report a case study of scleral necrosis following a Right eye recurrent nasal pterygium excision with adjunct beta irradiation which was managed with surgical repair and topical steroid, in a 35year old woman.

2.1. Case Report: A 35year old healthy young adult woman, not a known diabetic presented with history of right eye recurrent nasal pterygium. She subsequently had the recurrent pterygium excised with intraoperative adjunct single dose of 2,500 rad of beta irradiation applied on the bare sclera. Beta irradiation was applied with a strontum ${ }^{90}$ plaque. She was released on the same day, following surgery at which time there were no complications. There was no complaints or complications noted on the first postoperative day. She however presented a week later with history of pain and reduced vision in the right eye.

Right eye examination revealed a reduced visual acuity (VA) from preoperative 6/12 to Hand Movement (HM). There was a $2 \mathrm{~mm}$ by $3 \mathrm{~mm}$ nasal sclera defect with vitreous show. The cornea wasclear, anterior chamber was shallow, there was relative afferent pupillary defect, clear lens and a yellow fundal glow with poor fundal details. Left eye examination revealed VA of 6/5 with normal adnexa, normal anterior segment and normal posterior segment

She immediately had tectonic scleral patch to cover the scleral defect under local aneasthesia

A 6 by $5 \mathrm{~mm}$ corneoscleral graft was used to cover the scleral defect, sutured with 9-0 nylon with ten interrupted sutures. Auto conjunctival graft was used to cover the corneoscleral patch, also with 9-0 nylon in eight interrupted sutures. Anterior chamber was reformed with air bubble. Subconjunctival $20 \mathrm{mg}$ gentamicin and $2 \mathrm{mg}$ dexamethasone was given postoperative. Patient was placed on oral ciprofloxacin 500mg twice daily for a week and oral diclofenac 50mg twice daily for five days. 


\section{RESULT}

First day postoperative, VA was HM, eye was soft with fair eyelid opening, there was conjunctival hyperemia, the scleral patch with overlying patch was in situ with sutures holding, anterior chamber was well formed with air bubble, oval pupil, clear lens, yellow fundal glow but poor fundal detail was seen. The Intraocular pressure (IOP) were $04 \mathrm{mmHg}$ and $16 \mathrm{mmHg}$ in the right and left eye respectively. Patient was placed on Gutt dexamethasone and Gutt moxifloxacin.

Right eye VA improved to 6/60 a month postoperative, scleral patch was insitu ( Fig 1), cornea was clear, pupil was oval, there werefew iris pigments on the lens, media was clear and the disc was pink. CDR was 0.3, macular was normal and IOP was $11 \mathrm{mmHg}$.

Ocular Bscan done a month post operatively revealed bilateral clear lens with no retinal detachment or choroidal detachment (figure 2)

Bilateral fundus photograph also revealed bilateral flat retina (figure 3)

Right eye visual acuity further improved to $6 / 18$ two months post operatively

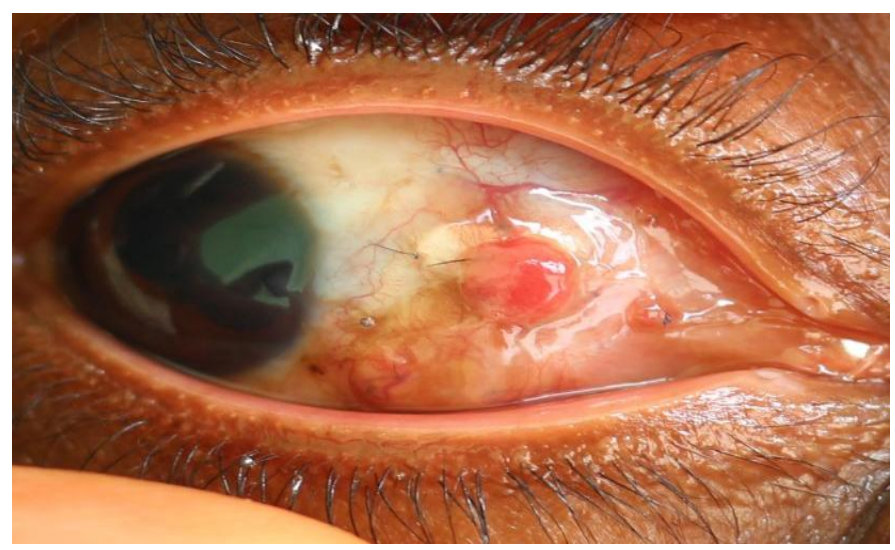

Figure 1: Postoperative scleral patch insitu.

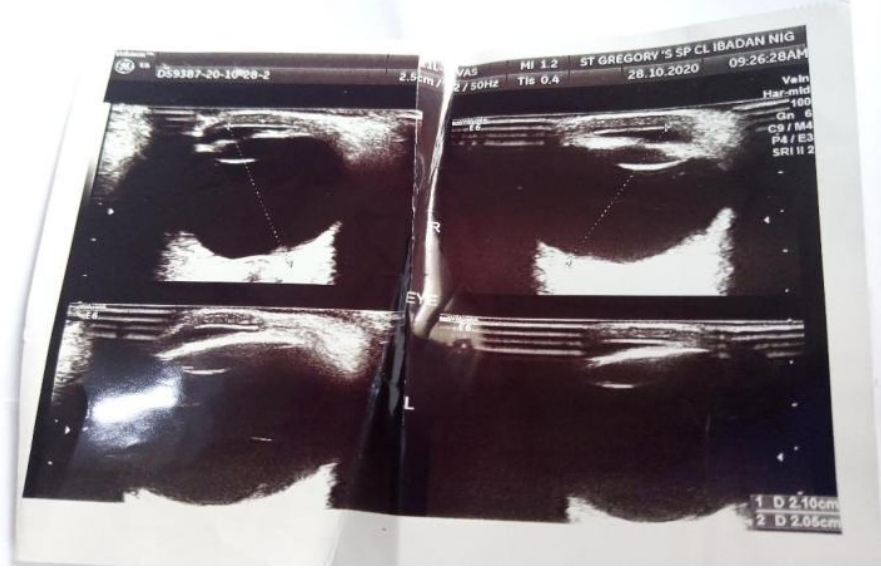

Figure 2: Postoperative Ocular Bscan showing a flat retina

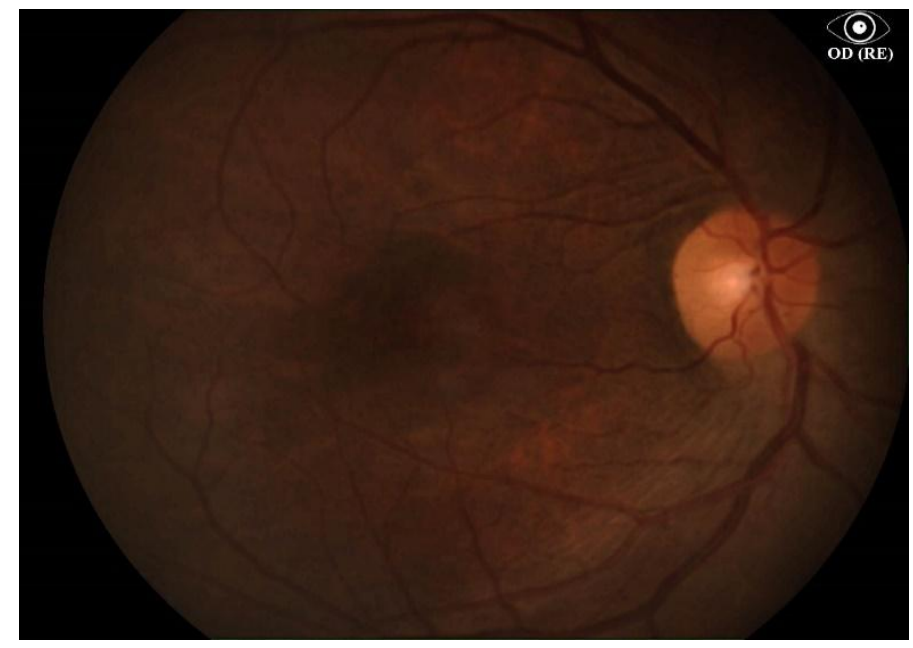

Figure 3: A fundus photograph showing a flat retina at 2 months post operation

\section{IV.DISCUSSION}

Scleral necrosis occurring after pterygium surgery with adjunctive treatment has been previously reported but with a different mode of management (Limma et al., 2017; Young et al., 2005; Safianik et al., 2002). The different adjunctive treatments usable during pterygium surgery include the use of beta irradiation, 5- Florouracil and mitomycin C (Limma et al., 2017; Young et al., 2005; Safianik et al., 2002; Alsagoff et al 2000; Ali., 2015). The occurrence of scleral necrosis following the application of these adjunct therapy has been ascribed to prolonged inhibition of wound healing after the use of these agents (Limma et al., 2017; Young et al., 2005; Safianik et al., 2002; Alsagoff et al., 2000).

Beta irradiation is an antiproliferative agent applied on the bare scleral after pterygium excision by using a radioactive applicator which emits beta rays which have only a very local penetration to a depth of less than one millimeter (Constable et al., 1998). Cellular p53 which is a neuropeptide that prevents cell replication in the presence of DNA damage have been found to be significantly increased following beta irradiation thereby inhibiting fibroblast proliferation(Constable et al., 1998).

In previous studies, high doses of systemic immunosuppressive therapy were used to arrest the progression of the melting process(Limma et al., 2017; Young et al., 2005; Alsagoff et al., 2000). However in this study, prompt treatment with scleral patch and topical steroid restored vision and averts unnecessary side effects that comes with systemic immunosuppressive therapy.

In this study, the corneo-scleral patch graft was covered with conjunctival autograft in order to help the ocular surface to reepithelialize rapidly and achieve a viable graft.

Safianik et al., (2002) also reported three cases with scleral necrosis following pterygium excision with adjunct Mitomycin $\mathrm{C}$ which were managed with graft surgery with 
good outcome. Sridhar et al managed surgically induced scleral necrosis with amniotic membrane graft and topical steroid with good outcome (Sridhar et al., 2002).

\section{CONCLUSION}

Prompt treatment with corneo-scleral patch and topical steroid can help avert the vision loss and possible loss of eye integrity that can follow surgically induced scleral necrosis. This mode of treatment averts the need for systemic immunosuppressive therapy.

\section{REFERENCES}

[1] Ali, AG., (2015). Scleral necrosis after pterygium excision and conjunctival autograft. Al-Azhar Assiut Medical Journal AAMJ, $13,229-234$.

[2] Alsagoff, Z., Tan, DTH., \& Chee S. (2000). Necrotising scleritis after bare sclera excision of pterygium. Br J Ophthalmol, 84, 1050-1052.

[3] Constable, PH., Crowston, JG., Occleston, NL., Cordeiro, MF., \& Khaw, PT., (1998). Long term growth arrest of human Tenon's fibroblasts following single application of beta radiation.Br $\mathrm{J}$ Ophthalmol, 82, 448-452.

[4] Linna, LU., Shiqiong, XU., Shengfang, GE., Chunyi, S., \& Zi, W., (2017). Tailored treatment for the management of scleral necrosis following pterygium excision. Exp Ther Med, 3, 845-850.

[5] Noureddin, G., \& Yeung, S,. (2016). The use of dry amniotic membrane in pterygium surgery. Clinical Ophthalmology, 10, 705-712.

[6] Ronald, R. (2018). Amniotic membrane grafts to reduce pterygium recurrence. Cornea, 37, 189-193.

[7] Safianik, B., Ben-Zion, I., \&Garzozi, HJ. (2002). Serious corneoscleral complications after pterygium excision with mitomycin C. Br J Ophthalmol, 86, 357-358.

[8] Sridhar, MS., Bansal, AK., \&Rao, GN., (2002). Surgically induced necrotizing scleritis after pterygium excision and conjunctival autograft. Cornea, 21, 305-307.

[9] Young, AL., Wong, SM., Leung, AT., Leung, GY., Cheng, LL., \& Lam, DS. (2005). Successful treatment of surgically induced necrotizing scleritis with tacrolimus. Clin Experiment Ophthalmol, $33,98-99$ 